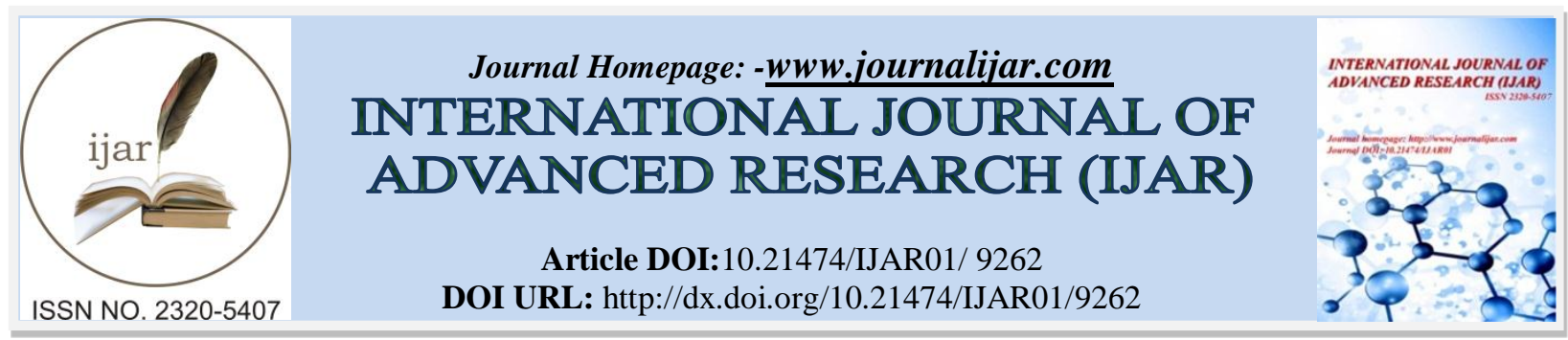

RESEARCH ARTICLE

\title{
THE EFFECTS OF WORKPLACE HARASSMENT ON CO-WORKER RELATIONSHIP AND WORK ENGAGEMENT: A DEVELOPING COUNTRY PERSPECTIVE.
}

\section{Md. Rokonuzzaman ${ }^{1}$, Md. Borak $\mathrm{Ali}^{2}$ and Mahibulla Moral ${ }^{1}$.}

1. Department of Management Studies, Bangabandhu Sheikh Mujibur Rahman Science and Technology University, Bangladesh.

2. Department of Marketing, Rajshahi University, Bangladesh.

\section{Manuscript Info}

\section{Manuscript History}

Received: 12 April 2019

Final Accepted: 14 May 2019

Published: June 2019

Key words:-

Workplace harassment; Co-worker relationship; Work engagement.

\begin{abstract}
This study aims to examine the effects of workplace harassment on the relationship amongst co-workers and their work engagement. It is one of the few studies to explain the effects of workplace harassment in a developing country perspective. Specifically, this study introduces coworker relationship as an endogenous factor for workplace harassment. It includes a total of 208 samples from Bangladesh of which $47 \%$ were female and 53\% were male. IBM AMOS based Structural Equation Modelling (SEM) was used to obtain the results using the latent factor approach. This study revealed that, the employees in Bangladesh have severe experiences of harassment in their workplace which negatively influences their relationship with co-workers and resulted in poor engagement in work. Given the mediating effect, maintaining through good co-worker relationship predicted less negative effect of workplace harassment on work engagement. It is also to worth that, $73 \%$ of the respondents reported that they were anyway harassed by their bosses and other co-workers and $27 \%$ reported that they were harassed by their customers. This study contributes to literature and organizational practices by explaining an important state that helps us understand the underlying association between workplace harassment and interactions amongst co-workers and employment of personal selves in work.
\end{abstract}

Copyright, IJAR, 2019., All rights reserved.

\section{Introduction:-}

Workplace harassment has been a well-researched and more concerning topic in organizations (Neall et al., 2014; Houshmand et al., 2012; Wu et al., 2012). Surprisingly, the prevalence of workplace harassment and associated troubles have not been well studied in the United States (Khubchandani et at., 2015); and in Asian countries, workplace harassment got less concern by managers in organizations (Rokonuzzaman \& Rahman, 2011). Whilst, most researches on workplace harassment originated from European countries (Khubchandani et at., 2015). This study tries out the results of a survey carried out about harassment in the workplace with reference to a developing country. Accordingly, the review in this study was carried out to bring forward the recent findings and underlying gaps in the literature for advancing knowledge on harassment at workplace and its consequences.

Corresponding Author:- Md. Rokonuzzaman.

Address:- Department of Management Studies, Bangabandhu Sheikh Mujibur Rahman Science and 
In practice, employee engagement has become a hot topic in recent years amongst popular business presses and consulting firms (Saks, 2006; Macey \& Schneider, 2008). Plus, it generated a great deal of interests to evidence an engagement-profit linkage (Cranshaw, 2009). Whereas, in the academic literature the issue has been relatively little known in respect of its antecedents and consequences (Saks, 2006). Usually, employees who are engaged in their work are fully connected with their work roles, teeming with energy, dedicated to their work, and immersed in their work activities. These gains make the employees franker to new information, more productive, and more willing to go for the extra mile. Plus, they seek their work environment amazed in order to stay engaged (Bakker, 2011).

Moreover, a notable importance on co-workers has been remarked by current organizational trends. Many of today's workplace draws on flatter construction of organizational structure and introduces more team-based approach for work (Lin Dar, 2009). In a meta-analysis, Chiaburu and colleague demonstrated coworker actions as a grave matter for their colleagues (Chiaburu \& Harrison, 2008). Also, co-workers support can affect individual employees' presence at work (Deery et al., 2010) and willingness to quit (Glambek et al., 1999). Nevertheless, some other important questions remain unanswered in this regard at the field level. To date, no study has been directed to combining whole range of actions originating from co-workers and individual work behaviors as the consequences of workplace harassment.

To fill this evidence gap, we propose that persons' relationship with their co-workers and the question of employing personal selves are critical amongst the factors those are the consequences of workplace harassment in organizations. In particular, we investigate whether those employees who are exposed to workplace harassment cost to poor co-worker relationship and reduce their work engagement? Plus, a second model was proposed to check if co-worker relationship has any mediating effect on the relationship between workplace harassment and work engagement. In the following sections, the constructs of co-worker relationship and work engagement as the targeted consequences of workplace harassment are presented by discussing the relevant literature. The following figure describes the proposed model for the effect analysis (Figure 1).

Figure 1:- The Hypothesized Model.

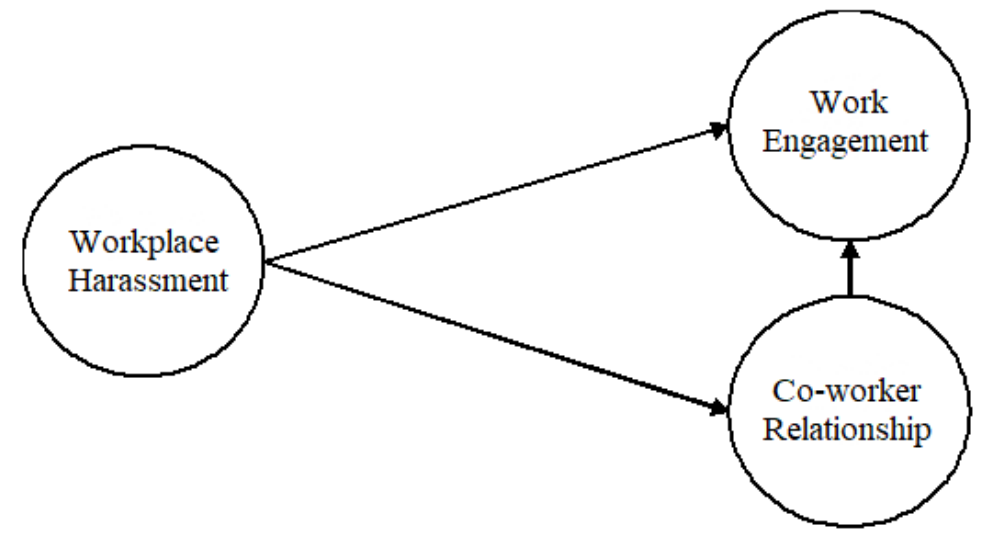

\section{Workplace Harassment and Its Consequences}

Workplace harassment has been considered as one of the most sensitive issues in organization (Tehrani, 2004). Becoming subject to be harassed in workplace produces unbitable stresses and due to this sometimes the victims may become psychologically disturbed. The surveys, studies and articles in the past decades on the issue of workplace harassment and its consequences mostly focused to retention strategies in a holistic manner to reduce turnover rates, motivational factors, work life balance, job satisfaction and very few to work engagement (Aguenza $\&$ Som, 2012). For example, in a research which sampled 350 respondents of whom majority are males and found that robust talent management planning, well supports of top management, fair salary, good safety and health insurance, training opportunity, career advancement, organization unity, a balance of work daily life, and other environmental factors were crucial factors that keep talent highly engaged to organizations (Piansoongnern et al., 2011). In another survey of 272 BPO/ITES employees, using a mixed method research design where the independent variable is talent management and dependent variable is employee engagement found that in the first 
phase low factor loadings indicated low engagement scores at the beginning of the career and at completion of 16 months with the organization. High factor loadings at intermediate stages of employment were indicative of high engagement levels, but the interview data reflected that this may mean high loyalty; but only for a limited time. In the second phase, factors loading indicated three distinct factors of organizational culture, career planning along with incentives and organizational support (Bhatnagar, 2007). Another qualitative based research implies that corporate cultures characterized by teamwork, pleasant working conditions, considerate treatment of employees' growth opportunities, flexible-working practices, and good leadership and management practices foster employee engagement (Rama Devi, 2009). A questionnaire survey by Andrew and colleague on 104 HR officers at the Inland Revenue Board of Malaysia found that employee communication, job satisfaction, organization commitment, intention to quit organization and citizenship behavior showed a significant relation with job engagement. Also, coemployee support as a major individual factor influences both measures of engagement and the work outcomes (Andrew \& Sofian, 2012). An empirical study based on the data collected from 340 front line employees from five organization across the service sector in Delhi-National Capital Region (NCR) found that human resource practices that drive engagement need to be fostered in organizations to drive performance (Popli \& Rizvi, 2016). Relationship with co-workers was researched as a predictor of work engagement in a research by Abraham in 2012. The sample size for the study was 120 employees and relationship with co-workers, the work itself, opportunities to use skills and abilities and relationship with immediate superior among others were the independent variables (Abraham, 2012). An analysis on physical, verbal or sexual harassment and turnover intention and job commitment using quantitative method was conducted by Avtac and colleagues in 2016 and found that, respondents who were exposed to higher workplace harassment significantly had higher rate of job turnover intention than who didn't (Aytac et al., 2016). A research on 364 nurses using structured questionnaire from Seoul metropolitan area on the issues of workplace bullying revealed that workplace bullying is associated with higher turnover intention and negatively correlated with leader-member exchange (Han et al., 2014). Another research on African context on harassment indicated that, sexual harassment positively influences psychological condition, health condition, trust and brand attachment in a significant and direct way. The notable finding of that research is that, sexual harassment indirectly influences workplace withdrawal and turnover intention (Sandada, 2013).

The research question arises in this study mainly is a focus on workplace harassment in Bangladesh, the victims' reactions with their co-worker, and the extent to which they engage their personal selves at work once they become subject to workplace harassment. Based on the above proposition, the first hypothesis was proposed as the following:

H1: Exposure to Workplace harassment will be negatively related to better Work engagement.

Besides, co-worker action has been the central issue in organizational studies due to its emergence of understanding the employers' control over coworkers' actions (Tan \& Lim, 2009). Plus, trust with co-workers is a predominant issue in lateral relationships. In literature, the leader-subordinate relations (Sue-Chan et al., 2012) and trust in coworker (Lau \& Liden, 2008) have been considered to have unique effects on focal employee behaviors at work (Ferres et al., 2004; Lin Dar, 2009). Whilst, it is to worth that, this study aimed to explain why employees might engage in exchanges with their coworkers and how their belief in coworkers can influence their positive or negative behaviors toward the coworkers and the organization as a whole. Therefore, based on the proposition, the second hypothesis to test understudy was proposed as follows:

H2: Exposure to Workplace harassment will be negatively related to better Co-worker relationship.

Moreover, due to preexisted workplace friendship, mutual trust, OCB and other personality traits there could be firm trustworthiness amongst colleagues in organizations. On this outset, this study predicted that, there could be the mediating effect of better co-worker relationship on the relationship between workplace harassment and work engagement, and the proposed hypothesis was as the following:

H3: Better Co-worker relationship will mediate the relationship between exposure to Workplace harassment and Work engagement.

\section{Methods:-}

\section{Participants and Procedure}

This research mainly used quantitative method to obtain the inputs for the test of hypotheses proposed in the previous section. Primarily, a survey questionnaire was developed, and simple random sampling was used to select the employees from middle and lower managerial levels from small-scale organizations. A total of 250 
questionnaires were distributed and 208 valid responses were collected. Descriptive statistics and structural equation modelling were used to predict and estimate the relationships. Test of normality and necessary reliability and validity tests were performed to explain the trustworthiness of the measurement instruments (included in result and analysis section). Among the participants, 53\% were males and 47\% were females and were aged between 24 and 56 years, and came from various organizations, including NGOs (29\%), medical services (11\%), garments (35\%), banking $(12 \%)$ and others $(13 \%)$.

It has been common to have missing values in assessment through self-report instruments (Jo et al., 2010). To confirm accuracy of the parameter estimates and to obtain valid result of the study, the problem of missing value must be properly addressed (Fox-Wasylyshyn et al., 2005). In researches, different methods can be applied to appropriately impute the missing values (Schmitt et al., 2015). In this study, imputation by mean was used to address the problem. However, in structural equation modelling, the testing of multivariate normality is a critical precondition. It determines the level of trustworthiness of the estimates and demonstrates the extent to which their factorial structures are valid (Byrne, 2001). In researches, obtaining the normality estimates usually resorts on descriptive statistics (Sartori, 2006). In standard deviation (SD) measure, about seventy percent of the data need to be lie within 1 SD and overall ninety percent should lie within 2 SD to explain that the data are symmetric and have a bell-shaped curve (Pearson \& Tukey, 1965). In skewness and kurtosis measures the estimated value should be within +1 and -1 for skewness and +3 and -3 for kurtosis (Kim \& White, 2004; Ghasemi \& Zahediasl, 2012). In this study, the results on test of normality for 208 samples shows that, the estimated value of SD for the items of workplace harassment ranges between 1.22 to 1.99 , skewness ranges between -.30 to 1.44 and kurtosis ranges between -1.50 to 1.37 . For work engagement the estimated SD ranges between 1.24 to 1.58 , skewness ranges between - .90 to .29 and kurtosis ranges between -1.48 to -.28 and for co-worker relationship measures the estimated SD ranges between 1.19 to 1.53 , skewness ranges between -.90 to .39 and kurtosis ranges between -1.40 to -.24 . Therefore, all the result for the normality tests are found between the cutoff range.

\section{Measures \\ Workplace Harassment}

Workplace harassment was assessed using the twenty-item measurement questionnaire used for Korean finance and service workers in 2016 (Lee et al., 2016). The questionnaire included a five-point Likert scale measures ranging from 1 (never) to 5 (almost everyday). In this study, the scale demonstrated acceptable factor loadings which ranges between .737 to .862 and the estimated Cronbach's Alpha was .897. The sample items included- 'I was humiliated or yelled at in front of others', 'I was insulted with demeaning expressions regarding my appearance or behavioral characteristics' and 'Someone talked behind my back or spread negative rumors about me'. It is however to worth that, amongst the 208 samples $73 \%$ of the respondents reported that they were anyway harassed by their bosses and other co-workers and $27 \%$ reported that they were harassed by their customers.

\section{Co-worker Relationship}

Co-worker relationship was assessed through an eleven-item questionnaire developed by Hain in 2005, in which participants were directed to think about their current job as they respond to the measures (Hain, 2005). In this study the responses were set on a five-point Likert scale, ranging from 1 (strongly disagree) to 5 (strongly agree) considering the type of respondents. Alike the previous, the estimates demonstrated favorable factor loadings for the measuring items which were ranged between .519 to .838 and the estimated Cronbach's Alpha was .825. The sample items included- 'I have good relationships with my coworkers', 'I like spending work hours with my coworkers' and 'The more I interact with my coworkers the better I enjoy my job'.

\section{Work Engagement}

Work engagement was assessed using the seventeen-item work and well-being survey questionnaire (Schaufeli \& Bakker, 2004). This seventeen-item scale is divided into three subscales, namely, absorption, dedication and vigor, with each subscale representing a dimension of work engagement. In this study the responses were set on a fivepoint Likert scale, ranging from 1 (almost never) to 5 (very often) considering the type of respondents. The estimates from 208 sample demonstrated favorable factor loadings for the measuring items which were ranged between .834 to .895 and the estimated Cronbach's Alpha was .892. The sample items included- 'At my work, I feel bursting with energy', 'I find the work that I do full of meaning and purpose' and 'I can continue working for very long periods at a time'. 


\section{Analysis and Discussion}

Given that this study dealt with latent factors (i.e. workplace harassment, co-worker relationship and work engagement), we used SPSS AMOS to examine the hypotheses understudy. To reduce the number of parameters, we used the item-parceling method (Bagozzi \& Edwards, 1998) on workplace harassment, co-worker relationship and work engagement. For each latent factor, a parameter that was linked with a variable was fixed as one. As a confirmatory method of assessing and modifying both the measurement and structural models, the fit indices in structural equation modelling (SEM) reflect how fit is the model to the data. While, the cutoff criteria for the fit indices ranges over parsimonious fit to incremental and absolute fit (Wheaton, 1987). After the first run of the measurement model understudy, the $\chi 2$ value showed an estimate of 237.300 with $\mathrm{d} f=62$ significant at the level of $\mathrm{p}<.001$. Hence, the $\chi^{2}$ to $\mathrm{d} f$ ratio was 3.827 , and to this estimate the model fit to the data was satisfactory. Likewise, the other comparative family indexes showed a good fit to the data $(\mathrm{NFI}=.858, \mathrm{RFI}=.822, \mathrm{IFI}=.891$, $\mathrm{TLI}=.862, \mathrm{CFI}=.890)$. Also, the RMSEA estimates indicated nearly good fit $(\mathrm{RMSEA}=.117, \mathrm{LO}=.101, \mathrm{HI}=$ .133 , PClose $=.000)$.

Through a careful look into the modification indices, it was identified that, tuning up of one item with the latent construct 'co-worker relationship' could improve the model fit. That same item (i.e. CR2) was also found to embrace the lowest factor loading in the model. Therefore, the case was dropped, and the new-tuned model was run. For the new measurement model, the $\chi 2$ value showed an estimate of 160.133 with $\mathrm{d} f=51$ significant at the level of $\mathrm{p}<.001$. Hence, the $\chi 2$ to $\mathrm{d} f$ ratio was 3.13 and met the cut-off criteria for model fit. Besides, the other fit indexes were changed to a better level of model fit $(\mathrm{NFI}=.895, \mathrm{RFI}=.846, \mathrm{IFI}=.925$, TLI $=.902, \mathrm{CFI}=.925)$. The RMSEA estimates also showed better fit compared to first measurement model $($ RMSEA $=.08, \mathrm{LO}=.086, \mathrm{HI}=$ .121 , PClose $=.000)$. Moreover, the validity and reliability plugin run on AMOS GUI reported acceptable validity (i.e. convergent validity: the estimate AVE must be greater than or equal to .50; divergent validity: the estimated AVE must be greater than estimated corresponding MSV) and reliability (i.e. composite reliability: the estimated CR* must be greater than or equal to .70; average variance extracted: the AVEs must be greater than or equal to .50) concerns, which are summarized in Table 1.

Table 1:- Validity and Reliability Measures

\begin{tabular}{|c|c|c|c|c|c|c|c|}
\hline Constructs & CR $^{*}$ & AVE & MSV & MaxR(H) & CR & WE & WH \\
\hline CR & 0.812 & 0.527 & 0.366 & 0.846 & 0.726 & & \\
\hline WE & 0.893 & 0.737 & 0.377 & 0.898 & $0.605^{* * *}$ & 0.858 & \\
\hline WH & 0.897 & 0.635 & 0.377 & 0.902 & $-0.562^{* * *}$ & $-0.614^{* * *}$ & 0.797 \\
\hline
\end{tabular}

*** Significant at $\mathrm{p}<.001 ; \mathrm{WH}=$ Workplace harassment; $\mathrm{WE}=$ Work engagement; $\mathrm{CR}=\mathrm{Co}$-worker relationship; $\mathrm{CR}^{*}=$ Composite reliability; $\mathrm{AVE}=$ Average variance extracted; $\mathrm{MSV}=$ Maximum shared variance; $\operatorname{MaxR}(\mathrm{H})=$ McDonald construct reliability.

However, given the inclusion of workplace harassment as the exogenous construct influencing the co-worker relationship and work engagement with direct effects and one regression line between co-worker relationship and work engagement, we initially tested the model with no line between the two endogenous constructs in the model. After the first run of the initial model (SM1), the $\chi^{2}$ value showed an estimate of 184.196 with $\mathrm{d} f=52 \mathrm{at} \mathrm{p}<.001$ level of significance. Hence, the $\chi 2$ to $\mathrm{d} f$ ratio was 3.542 , which is slightly close to the cut-off criteria (i.e. 1 to 3 ). Also, the other fit indexes showed a slightly good fit to the data $(\mathrm{NFI}=.881, \mathrm{RFI}=.849, \mathrm{IFI}=.912, \mathrm{TLI}=.887, \mathrm{CFI}$ $=.911$ ). Whereas, the RMSEA estimates showed a moderately good fit of the structural model (RMSEA $=.111$, LO $=.094, \mathrm{HI}=.128$, PClose $=.000)$. By looking into the modification indices, the hypothesized line between coworker relationship and work engagement was added and the second model was run.

In the second model (SM2), the $\chi^{2}$ value showed an estimate of 163.133 with $\mathrm{d} f=51$ at $\mathrm{p}<.001$ level of significance. Hence, the $\chi 2$ to $\mathrm{d} f$ ratio was 3.199 , which is again slightly close to the cut-off criteria (i.e. 1 to 3 ). Also, the other fit indexes showed a slightly good fit to the data $(\mathrm{NFI}=.895, \mathrm{RFI}=.864$, IFI $=.925, \mathrm{TLI}=.902$, CFI $=.925$ ). Whereas, the RMSEA estimates showed a moderately good fit of the structural model (RMSEA $=.103$, LO $=.086, \mathrm{HI}=.121$, PClose $=.000)$. Alike previous, by looking into the modification indices it was found that, drawing a double-headed arrow (i.e. covariance) between the residuals of two measurement variable (WH2 and WH4) of the workplace harassment would improve the model fit. The modified model with an added covariance line (SM3) indicated good fit to the data in $\chi^{2} / \mathrm{d} f$ estimate. (i.e. $\chi^{2}=140.784, \mathrm{~d} f=50, \mathrm{p}<.000 ; \chi^{2}$ to $\mathrm{d} f$ ratio $=2.816$ ). 


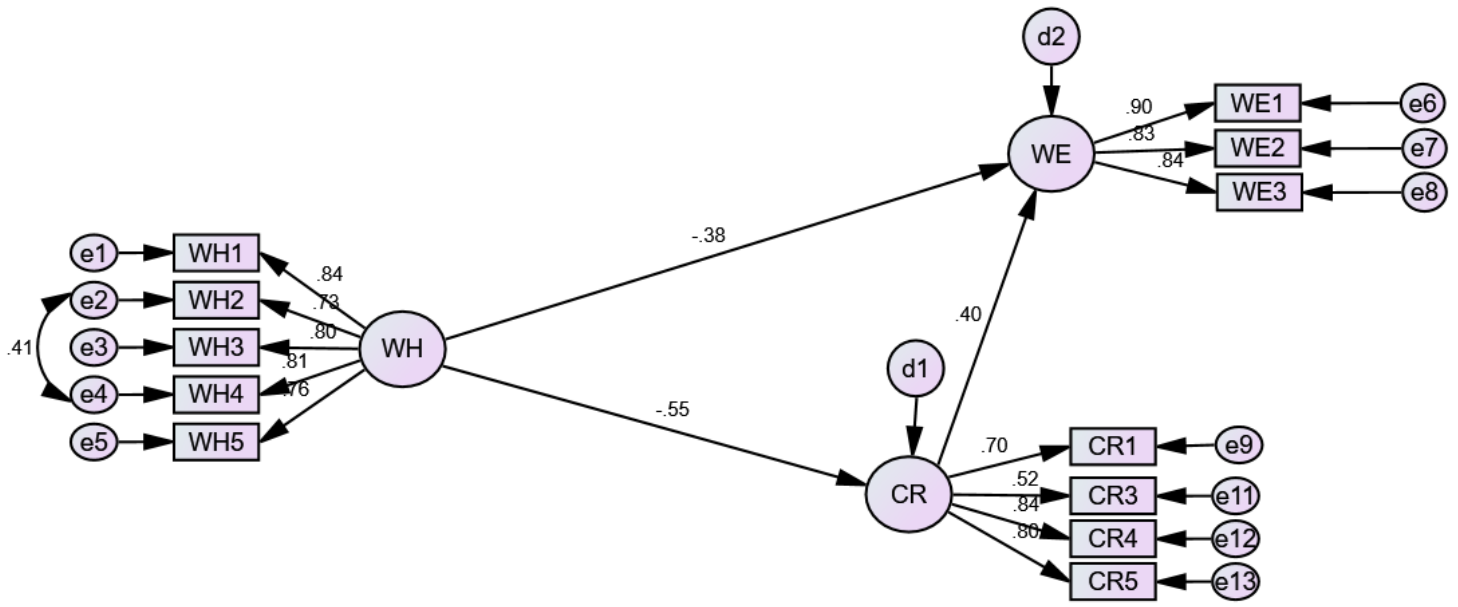

*AMOS GUI shows rounded up value for the estimates.

Besides, the other fit indexes were changed to a finer level of model fit $(\mathrm{NFI}=.909, \mathrm{RFI}=.880, \mathrm{IFI}=.940$, TLI $=$ .919 , CFI = .939). Plus, compared to initial structural model (SM2), the RMSEA estimates showed better fit for the model SM3 $(\mathrm{RMSEA}=.084, \mathrm{LO}=.076, \mathrm{HI}=.112$, PClose $=.000)$. Based on the final model, the SEM analyses confirmed all the proposed hypotheses. Workplace harassment was negatively related to work engagement $(\beta=-$ $.383, p<.001)(\mathrm{H} 1)$ and it also negatively related to co-worker relationship $(\beta=-.548, p<.001)(\mathrm{H} 2)$. Whilst, coworker relationship positively predicted work engagement $(\beta=.395, p<.001)$. Moreover, the standardized indirect effect (i.e. mediated by co-worker relationship) of workplace harassment on work engagement showed an estimate of -.217 and hence hypothesis H3 was also accepted. The results from the test are summarized in Table 2.

Table 2:- The Results of Hypotheses Test

\begin{tabular}{|l|c|c|c|}
\hline Paths & Beta Coefficients & P value & Decision \\
\hline$W H \rightarrow W E$ & -.383 & $<.001$ & Supported \\
\hline$W H \rightarrow C R$ & -.548 & $<.001$ & Supported \\
\hline$W H \rightarrow C R \rightarrow W E$ & -.217 & $<.001$ & Supported \\
\hline
\end{tabular}

Overall, this research highlighted the bitter reality of organizational practices in Bangladesh that failed to implement the guidelines on workplace harassment. Specifically, the results from structural equation modelling in this study concurs many of the recent research studies. For example- a survey questionnaire designed and distributed to 450 respondents demonstrated deleterious effect of workplace harassment on work performance (Lin et. al., 2016). It also leads to a low-quality work environment (Einarsen et at., 2008) and exposes the employees towards offensive behavior and sexual coercion (Ali et al., 2015). The findings of this research also concur Thirlwall and colleagues' finding that, harassed employees produce lower job performance (Thirlwall et al., 2009).

Specifically, the result of the test of hypotheses demonstrated that, workplace harassment is a crushing issue in organizations ranges to service and manufacturing. It threatens relationship amongst colleagues and victim severely loses his/her ability to employ personal selves into work and eventually fails to contribute to organizational goals. The study also revealed that, maintaining through good co-worker relationship in workplace diminishes the detrimental effects of workplace harassment on work engagement of the employees.

\section{Conclusion and Further Research:-}

In developing countries special focus and effort is required specifically on workplace harassment issues, since it was found to have severe damaging effect on co-worker relationship and significantly higher negative impact on employees' work engagement. Organizations must to focus on presenting a great environment for employees to work and promote programs that would enhance peer relationships. Also, since workplace harassment is a concerning and frequently happening matter in every type of organization in developing countries, future studies 
need to include perpetrator characteristics and harassment severity to convey the clear picture to both the practitioners and policy makers about the measures that needs to be taken to stop harassment at workplace. Questions also need to be raised on the effectiveness of written anti-harassment policies for influencing organizational responses to harassment. Further researchers should focus on quality methodology in order to obtain an in-depth view of the most common type of harassment faced. Moreover, future researches should concern previously untapped segments of people such as students, maids or servant at home and students in madrassas that are vulnerable to harassment. This study based on very few types of professional respondents. A wide rage of professionals can be included in order to know if there are any variation in harassment and its consequences to colleague relationship and work engagement. A longitudinal study is also recommended for future researches in which data should be collected from same respondents over a long period of time so that a vulnerable insight about the trends and changes in the perception of harassment can be uncovered.

However, this study is not devoid of limitations. One basic limitation of this study was the sample size, which is supposed to be lower to analyze the overall scenario of workplace harassment and its effects on employee engagement and coworker's relationship. The second limitation was the suspense that the respondents could hide their exact experience of being subject to workplace harassment from the fear of losing personal and organizational reputation. The third limitation is that, the participants surveyed all come from Bangladesh. Hence, generalizability becomes an issue of the role of cultural factors (e.g. individualistic vs collectivist) in workplace harassment situations.

Moreover, during the survey the participant reported that the workers have defective ethics and the management herein Bangladesh practices traditional type of treatment for harassment issues. This paper is expected to be a groundwork for academics and practitioners in developing countries to explain and understand the underlying association between workplace harassment and quality of interactions amongst colleagues and bringing of personal selves at work.

\section{Conflict of Interests}

The authors declare no conflict of interest.

\section{Reference:-}

1. Abraham, S. (2012). Job Satisfaction as an Antecedent to Employee Engagement. SIES Journal of Management, 8(2).

2. Aguenza, B.B. \& Som, A.P.M. (2018). Motivational factors of employee retention and engagement in organizations. IJAME.

3. Ali, S.R.O., Zakaria, Z., Zahari, A.S.M., Said, N.S.M. \& Salleh, S.M. (2015). The Effects of Sexual Harassment in Workplace: Experience of Employees in Hospitality Industry in Terengganu, Malaysia. Mediterranean Journal of Social Sciences, 6(4), p.689.

4. Andrew, O.C. \& Sofian, S. (2012). Individual factors and work outcomes of employee engagement. ProcediaSocial and Behavioral Sciences, 40, pp.498-508.

5. Aytac, S., Dursun, S. \& Akalp, G. (2016). Workplace violence and effects on turnover intention and job commitment: a pilot study among healthcare workers in Turkey. European Scientific Journal, ESJ, 12(10).

6. Bagozzi, R. P., \& Edwards, J. R. (1998). A general approach for representing constructs in organizational research. Organizational Research Methods, 1, 45-87.

7. Bakker, A.B. (2011). An evidence-based model of work engagement. Current directions in psychological science, 20(4), pp.265-269.

8. Bhatnagar, J. (2007). Talent management strategy of employee engagement in Indian ITES employees: key to retention. Employee relations, 29(6), pp.640-663.

9. Byrne, B.M., (2001). Structural equation modeling with AMOS, EQS, and LISREL: Comparative approaches to testing for the factorial validity of a measuring instrument. International journal of testing, 1(1), pp.55-86.

10. Chiaburu, D. S., \& Harrison, D. A. (2008). Do coworkers make the place? Conceptual synthesis and metaanalysis of lateral social influences in organizations. Journal of Applied Psychology, 93(5), 1082-1103.

11. Cranshaw, L. (2009). Workplace bullying? Mobbing? Harassment? Distraction by a thousand definitions. Consulting Psychology Journal Practice and Research, 61(3), 263-267.

12. Deery, S. J., Iverson, R. D., \& Walsh, J. T. (2010). Coping strategies in call centres: Work intensity and the role of co-workers and supervisors. British Journal of Industrial Relations, 48(1), 181-200. 
13. Einarsen, S., Raknes, B.R.I. \& Matthiesen, S.B. (1994). Bullying and harassment at work and their relationships to work environment quality: An exploratory study. European journal of work and organizational psychology, 4(4), pp.381-401.

14. Ferres, N., Connell, J., \& Travaglione, A. (2004). Co-worker trust as a social catalyst for constructive employee attitudes. Journal of Managerial Psychology, 19(6), 608-622.

15. Fox-Wasylyshyn, S.M. and El-Masri, M.M., (2005). Handling missing data in self-report measures. Research in nursing \& health, 28(6), pp.488-495.

16. Ghasemi, A. and Zahediasl, S., 2012. Normality tests for statistical analysis: a guide for nonstatisticians. International journal of endocrinology and metabolism, 10(2), p.486.

17. Glambek, M., Matthiesen, S. B., Hetland, J., \& Einarsen, S. (2014). Workplace bullying as an antecedent to job insecurity and intention to leave: a 6-month prospective study. Human Resource Management Journal, 24(3), 255-268.

18. Hain, C. A. (2005). Co-worker relationships: Using a new measure to predict health related outcomes. Archives Canada, Published Heritage Branch, 395 Wellington Street, Ottawa, Canada. pp01-62.

19. Han, M.R., Gu, J.A. \& Yoo, I.Y. (2014). Influence of workplace bullying and leader-member exchange on turnover intention among nurses. Journal of Korean Academy of Nursing Administration, 20(4), pp.383-393.

20. Houshmand, M., O’Reilly, J., Robinson, S., \& Wolff, A. (2012). Escaping bullying: The simultaneous impact of individual and unit-level bullying on turnover intentions. Human Relations, 65, 901-918.

21. Jo, B., Ginexi, E.M. and Ialongo, N.S., (2010), Handling missing data in randomized experiments with noncompliance. Prevention Science, 11(4), pp.384-396.

22. Khubchandani, J. \& Price, J.H. (2015). Workplace harassment and morbidity among US adults: results from the National Health Interview Survey. Journal of community health, 40(3), pp.555-563.

23. Kim, T.H. and White, H., 2004. On more robust estimation of skewness and kurtosis. Finance Research Letters, 1(1), pp.56-73.

24. Lau, D. C., \& Liden, R. C. (2008). Antecedents of coworker trust: Leaders' blessings. Journal of applied psychology, 93(5), 1130.

25. Lee, M., Kim, H., Shin, D., \& Lee, S. (2016). Reliability and validity of the workplace harassment questionnaire for Korean finance and service workers. Annals of Occupational and Environmental Medicine, 28(1), 45. DOI 10.1186/s40557-016-0133-0

26. Lin Dar, O. (2009). Trust in coworkers and employee behaviors at work.

27. Lin, P.K., Tran, T.T., Lin, P.C. \& Li, S.Y. (2017). Gender discrimination misconducts perceived by female workers of Vietnamese industries. In Service Systems and Service Management (ICSSSM), 2017 International Conference on (pp. 1-4). IEEE.

28. Macey, W. H., \& Schneider, B. (2008). The meaning of employee engagement. Industrial and organizational Psychology, 1(1), 3-30.

29. Neall, A.M. \& Tuckey, M.R. (2014). A methodological review of research on the antecedents and consequences of workplace harassment. Journal of Occupational and Organizational Psychology, 87(2), pp.225-257.

30. Pearson, E.S. and Tukey, J.W., 1965. Approximate means and standard deviations based on distances between percentage points of frequency curves. Biometrika, 52(3/4), pp.533-546.

31. Piansoongnern, O., Anurit, P. \& Kuiyawattananonta, S. (2011). Talent management in Thai cement companies: A study of strategies and factors influencing employee engagement. African Journal of Business Management, 5(5), pp.1578-1583.

32. Popli, S. \& Rizvi, I.A. (2016). Drivers of employee engagement: The role of leadership style. Global Business Review, 17(4), pp.965-979.

33. Rama Devi, V. (2009). Employee engagement is a two-way street. Human resource management international digest, 17(2), pp.3-4.

34. Rokonuzzaman, M. \& Rahman, M. M. (2011). Workplace Harassment and Productivity: A Comprehensive Role of Strategic Leadership. Journal of General Education. 1(Dec). pp.41-50.

35. Saks, A.M. (2006). Antecedents and consequences of employee engagement. Journal of managerial psychology, 21(7), pp.600-619.

36. Sandada, M. (2013). The influences of sexual harassment on health, psychological condition, work withdrawal and turnover intention in South Africa. Journal of Business, 1(2), pp.84-72.

37. Sartori, R., 2006. The bell curve in psychological research and practice: myth or reality? Quality and Quantity, 40(3), pp.407-418.

38. Schaufeli, W., \& Bakker, A. (2004). Utrecht Work Engagement Scale Preliminary Manual [Version 1.1, December 2004]. Utrecht University, Occupational Health Psychology Unit. Retrieved January, 17, 2013. 
39. Schmitt, P., Mandel, J. and Guedj, M., (2015). A comparison of six methods for missing data imputation. Journal of Biometrics \& Biostatistics, 6(1), p.1.

40. Sue-Chan, C., Au, A. K., \& Hackett, R. D. (2012). Trust as a mediator of the relationship between leader/member behavior and leader-member-exchange quality. Journal of World Business, 47(3), 459-468.

41. Tan, H. H., \& Lim, A. K. (2009). Trust in coworkers and trust in organizations. the Journal of Psychology, 143(1), 45-66.

42. Tehrani, N. (2004). Bullying: a source of chronic post traumatic stress?. British journal of guidance \& counselling, 32(3), 357-366.

43. Thirlwall, A., Haar, J.M. \& Zom, T. (2009). Bullying in New Zealand's Higher Education Sector: The Impact on Job Satisfaction and Performance.

44. Wheaton B., 1987. Assessment of fit in overidentified models with latent variables. Sociological Methods and Research. 16: pp.118-154

45. Wu, L.-Z., Yim, F. H.-k., Kwan, H. K., \& Zhang, X. (2012). Coping with workplace ostracism: The roles of ingratiation and political skill in employee psychological distress. Journal of Management Studies, 49, 178-199. 